\title{
A market of accents
}

\section{Jan Blommaert}

Received: 24 April 2008/Accepted: 12 February 2009/Published online: 16 April 2009

(C) The Author(s) 2009. This article is published with open access at Springerlink.com

\begin{abstract}
This paper describes the cultural semantics of internet courses in American accent. Such courses are offered by corporate providers to specific groups of customers: people in search of success in the globalized business environment. The core of such courses is an order of indexicality which stresses uniformity and homogeneity, producing an invisible accent that replaces existing 'foreign' (i.e. authentic, biographic) accents. It is a new form of commodified dialectology, which differs quite substantially from common state and academic attitudes towards dialects and accents. The procedures used by such private providers are instances of language policing aimed at the infinitely small stuff of language: pronunciation. They show the interplay of different institutional actors in producing language norms within a globalized environment, and they raise issues of subjectivity and agency.
\end{abstract}

Keywords Internet · Accent · American - Globalization · Language policing

\section{Introduction}

Language policy revolves around the production and enforcement of norms for language use, and its success is measured by the degree to which policy-preferred norms are accepted and spread. Traditionally, the state is the major player in the field of language policy. It regulates which language(s) and forms of literacy are 'official' and 'national', and it imposes rules and constraints on the use of languages and scripts in its realm. Usually, note, the state was and is concerned with languages, that is, with one layer of linguistic variation, and the state would regulate the use of one, or a handful of official languages in a range of institutions-education, legislation,

\footnotetext{
J. Blommaert $(\bowtie)$

University of Jyväskylä, Tilburg University, Jozef Balstraat 11, 2600 Berchem, Belgium e-mail: blommie@skynet.be
} 
the courts, and administration. The tendency there would generally be 'monoglot', strengthening the hegemony of the official languages and implicitly (or explicitly in some instances) proscribing the use of other languages (Bourdieu 1991; Silverstein 1996).

The state, however, always had to share the space of norm definition and normative conduct with other actors - the family is one very important such actors, while civil society actors such as churches are others. Media, traditionally, by and large supported the 'official' norms imposed by the state and would follow the regulation of languages in their operations. Note again that all of this pertains to one level of sociolinguistic variation: the level of inter-language variation. When it comes to intra-language variation-dialects and accents in the languages regulated by the state-we see a more flexible and less rigid picture, with some freedom for the individual to articulate identities through intra-language variables such as accent and dialect. At the national level, such levels of intra-language variation are very often seen as the fabric of national identity and local (sub-state) authenticity and often cherished as such (see e.g. Elmes 2005). Thus, the state would prescribe the use of English in schools, but would not be overly worried if the result of this schooling were English with an Indian, Chinese, Nigerian, etc. accent. This counts even in places where hard choices were made between US and UK versions of English as the official version to be taught: the fact that students speak American English with an Indian accent is not usually a cause for concern for the state, and the state would leave its pupils alone if they speak this layered cake of accents.

I have to cut quite a few corners here, but the point I wish to make is that (1) the state is traditionally a very powerful actor in setting language norms; but (2) the state was never the only player in the field of language normativity; it always was (and remains) a major player, but never a completely hegemonic player; there is always a form of polycentricity, a division of labour between the state and other actors in this field, and formal language policies compete with the language politics of other actors in complex webs of language policing activities; (3) the language policies of the state are traditionally aimed at 'languages' only; the coexistence of a multitude of dialects and accents in the official languages is usually not seen as an issue.

I will use these general introductory remarks as the backdrop for an argument that runs as follows. The traditional tolerance of state policies towards intralanguage variation such as dialects and accents is not matched by the politics of language of globalized, private enterprise actors. While the state focuses on language, new actors of language commodification focus on accent and discourse, thus creating a market in which sharp distinctions between speaking right and speaking wrong are articulated. Such distinctions draw on globalized orders of indexicality, normative complexes in which imageries of global success and failure are used, and Englishthe language that defines globalization-is of course the core of such orders. The outcome of this is a competitive market not just of English but of English accents which defies the traditional tolerance of the state policies, as well as popular (and academic) perceptions of accent as producing authenticity. It creates a new commodified dialectology and raises quite complex issues of normativity and identity, as well as of the shifting balance between formal language policies and 
equally formalized language politics in an age of globalization. It is an instance of Foucaultian 'policing' - the concept described in the introductory chapter to this volume as the rational production of order-and it works through an infinitely detailed attention to conduct (what Foucault [2006, 2007] called 'the care of the self', the perpetual micro-practices of subjectivity). Accent courses produce a regimented subject that is subjected to rules of 'normal' speech-speech that is invisible because it is uniform and homogeneous. Let us now examine the procedures by means of which this subjectification is put into effect.

\section{The internet and the commodification of accent}

Replacing to some extent the older industry of correspondence courses, the internet offers a wide and virtually uncontrolled space for language learning packages. They come in all shapes and sizes, and in this paper I will be focusing on websites offering courses in American accent. Some of these courses are targeted at Human Resources departments of large corporations, others are directed at individual customers, but all of them are offered under the same banner and through the same public channel-the internet. In that sense, they form a coherent body of objects, differences in design and target audience notwithstanding. I chose this object because the internet courses manifestly bank on two different things: (1) a general phenomenon of the worldwide 'stampede towards English' (de Swaan 2001) inspired by the global perception of English as the language that defines upwardly mobile trajectories; (2) a more specific phenomenon in which a particular imagery of the US and American cultural symbols is being seen as the forefront of globalization and the real key to upward global mobility. In other words, we get the so-called 'McDonaldization' of the world caught metonymically in packages for acquiring an American-sounding variety of English. Together, these points form a cultural semantics in which American accent is seen as normal, that is, as normative, and its regulated (or 'policed') use is proposed as an instrument for success.

What is spread is, of course, not just the product but also the adjectives used to qualify it, not just the language as linguistic structure but the language as a densely loaded ideological package, something that is far more than a language but also an acquirable imagery of the Self as being 'in the world'. Let me note from the outset that, although American accent websites may offer us the most outspoken examples of such dense ideological packaging, websites offering packages in other languages and varieties do the same, be it slightly less explicitly. They all offer language and the social trajectories it is supposed to provide or open. American accent websites are not unique but illustrative of a broader pattern of ideological packaging of commodified languages and varieties. We should also observe right from the start that these websites never offer ' $a$ ' language in its totality. What they offer is a register-a specific bit of language tailored to the immediate needs or desires of the customers (cf. Silverstein 2003a; Agha 2005, 2007). What is offered is something that gives the impression of language, a pragmatic and metapragmatic component to language competence that indexically induces the right ideological package. The 
point is not to learn American English, but to sound like an American. The language policing here operates on sub-language objects, on intra-language variation.

Consider example 1, taken from a website called 'American Accent Now' (www.American-accent-now.com).

Example 1

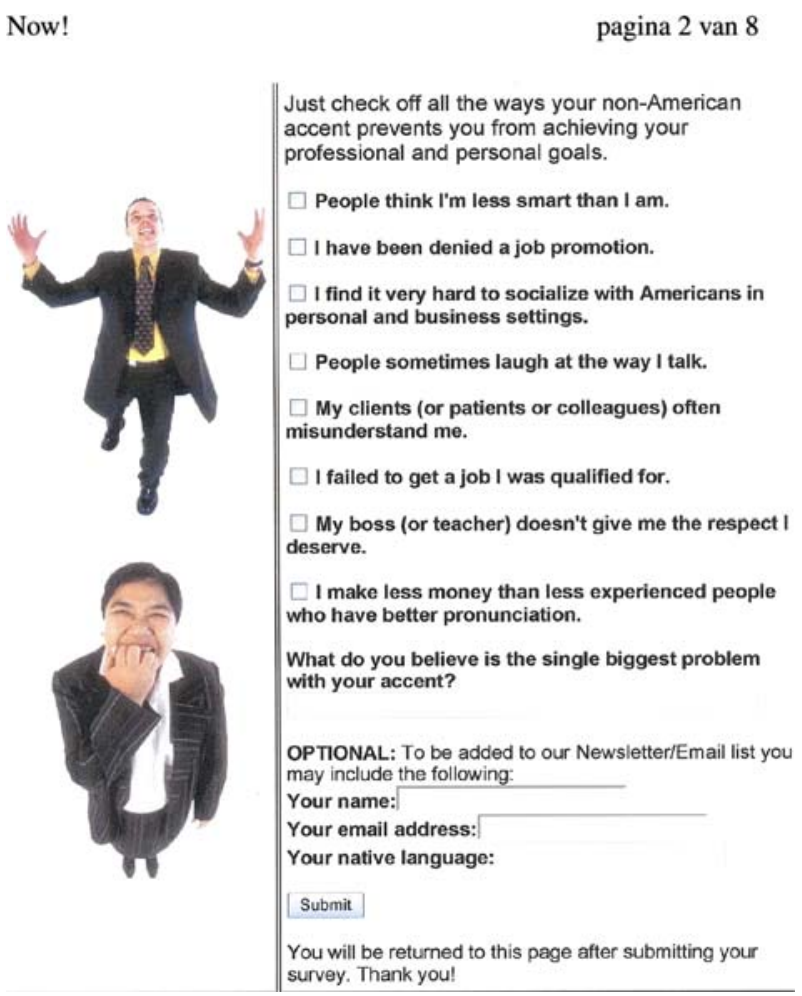

We see several things here. First, of course, we see two figures: a manifestly happy young white man, and a manifestly frustrated Asian woman. We can assume that the man has acquired an American accent (or had one right from the start) and that the Asian woman hasn't. The reason why she is frustrated can be read from the boxes one can check to demonstrate the ways in which a "non-American accent prevents you from achieving your professional and personal goals". Respondentsprospective customers - are requested to identify the "single biggest problem with your accent". The two categories can be divided as follows:

Professional

- I have been denied a job promotion

- My clients (or patients or colleagues) often misunderstand me

- I failed to get a job I was qualified for

- My boss (or teacher) doesn't give me the respect I deserve 
- I make less money than less experienced people who have a better pronunciation Personal

- People think I'm less smart than I am

- I find it very hard to socialize with Americans in personal and business settings

- People sometimes laugh at the way I talk

We now begin to discover the strange world we have entered. It is a world in which indexical values and social effects of language-usually tacit ideological features of language use-are made very explicit both in text and in images. Pronunciation is the key to obtaining the jobs one deserves and earning the money one is entitled to. An image of personality is invoked that makes this reduction possible: the prospective customer is already smart, entitled to better jobs and a superior income, and entitled to respect from one's superiors. So acquiring the accent will, so to speak, release all of these qualities to be seen by everyone. Acquiring an American accent will, in the eyes of the interlocutors, turn you into the person you really are.

Not everyone is a prospective customer of course. As we could see in the images used by American Accent Now, the frustrated subject was Asian and the happy one was what is known in the US as a 'Caucasian'. Websites make general targeted statements about 'strong foreign accents':

Example 2

"A strong foreign accent can prevent you from achieving your professional or personal goals and reaching your full potential. People shouldn't have to ask you to repeat what you said. In today's competitive corporate environment, clear pronunciation and correct grammar are a must." (Accurate English, www.accurateenglish.com).

And what is meant by 'strong foreign' accent is often documented in the FAQ or Testimonials pages of such websites, and almost invariably this is done by reference to 'national' accents. Some European accents such as French, German and even British accents are seen as particularly prone to misunderstanding, Asian accents such as Indian, Chinese and Japanese accents naturally move in the danger zone of globalized comprehensibility, and Middle Eastern accents are problematic throughout. They are problematic in contacts with 'native speakers':

Example 3

"Our accent reduction and American pronunciation courses will teach you to create the sounds of Standard American English and give you greater confidence in your communication skills with native speakers of English." (Accurate English)

Example 4

"[Testimonial from an 'Iranian dental student'] Hi, my name is Sanaz. About a year ago when I came to the U.S., I was very confused. I was in culture shock. Thanks to God, it happened to me to meet very lovely people. They gave me courage to deal with all new things, as well as they helped me to improve my English, and gave me confidence to speak English. Among them 
two people were so special for me-Sheri and Mark [the Accent Workshop trainers]. Not only they were fabulous teachers, they were very helpful friends. You can always trust their opinion. I'll never forget the great influence that Sheri and Mark have on my English. I'm really happy to meet them." (The American Accent Workshop, www.accentworkshop.com)

Sanaz experienced 'confusion' and 'culture shock' upon his arrival in the US, and the American accent course gave him 'courage' and 'confidence' to speak American English, and this capacity clearly helped him overcome his initial feelings. Note the frequent references to 'feelgood' factors such as 'confidence'. Speaking in an American accent makes people more confident in contacts with their American native-speaker counterparts:

\section{Example 5}

[Testimonial from a Spanish male Laboratory manager] "The Accurate English accent reduction courses should be a "must" for all professionals whose foreign accent gets in the way of clear communication. Taking the courses has greatly improved my pronunciation of American English sounds and made a big difference in my speech. My presentations at work are much better. I speak with more confidence and authority." (Accurate English)

\section{Example 6}

[Testimonial from an Israeli male computer consultant] "Before I started taking the classes, I couldn't pronounce certain vowel sounds correctly. Lisa [the trainer] identified the issues and taught me to listen and to express myself in a native way. Her customized method allowed me to quantify my weekly improvements. After a relatively short time, I noticed major progress in the way I speak. This lead to an unexpected increase in my confidence when communicating. I highly recommend the American Pronunciation course" (Accurate English)

Example 7 (The benefits of Accent Modification can be yours!)

- Clear, understandable speech

- Efficient, effective communication

- Career opportunities

- Improved job performance

- Successful public speaking

- More confidence

(Advance American Accent Training, www.advanceamericanaccent.com)

The 'confidence' promised or reported in these examples is a mixture of personal and professional features. People are more confident in general, they feel better after having taken the courses, and they also perform better in their jobs as well. The Spanish Laboratory Manager reported significant improvements in his presentations at work, and Advance American Accent Training promises not just 'more

\footnotetext{
1 Note also the indexical currency of authenticity expressed in 'thanks to God': Sanaz is Iranian, therefore he is Muslim, and Muslims use expressions like that.
} 
confidence' but also 'career opportunities' as well as 'improved job performance'. The implicit image is that of a 'professional', someone whose job is a central part of his/her life, and for whom professional unhappiness is equal to personal unhappiness. Most websites, thus, would suggest mixtures of professional and personal results for their accent courses, and we see a sort of continuum here, some websites suggesting more professional benefits than personal ones. Consider example 8 from the Accent Reduction Institute (www.lessaccent.com), a website that shouts "Lose your accent in 28 days!":

Example 8

"The Accent Reduction Institute (ARI) is the industry leader in American Accent Training, providing non-native English speakers with proven techniques to quickly master English pronunciation. ARI provides the tools to help people maintain their unique cultural identity while:

- Eliminating language barriers and miscommunications

- Increasing sales and profitability

- Communicating expertize to customers

- Building strong teams

- Increasing efficiencies

- Raising self-confidence"

'Self-confidence' has been pushed into a small corner here, and the main advertisement claims are about professional aims. Note, however, that customers can "maintain their unique cultural identity". I shall come back to that below. Communicaid (www.communicaid.com), in the meantime, is clear about its business-oriented efficiency:

Example 9

"Why American Accent Training? With the proliferation of offshore operations in locations as diverse as India, the Philippines, South Africa and China, organizations need to ensure that their offshore employees are able to communicate effectively with customers and colleagues alike. A vital ingredient of successful communication for your overseas staff is their accent when speaking English."

"The impact of First Language Influence (FLI) on an offshore employee's accent can not be underestimated. American Accent training from Communicaid will help your overseas staff to minimize the influence of their first language while maximizing their communication with your customers through a neutral accent. Whether through online American Accent Training courses, virtual American Accent training or face-to-face accent instruction, Communicaid offers scaleable American accent training solutions for your organization's offshore operations."

"A Communicaid American Accent Training course will provide your offshore personnel with the ability to:

- Communicate more efficiently and effectively with customers and colleagues by reducing their first language influenced accent 
- Build rapport and empathy and strengthen relationships with customers and colleagues through more successful communication

- Enhance your customer experience and satisfaction"

The target groups are here, clearly, the ever-increasing workforce of international call centers, and most of the American accent websites would make explicit or implicit reference to call centers as a target or a success story. Thus, the Testimonials page of the Pronunciation Workshop (www.pronunciationworkshop. com) reports:

\section{Example 10}

"This is by far, the MOST EFFECTIVE English Pronunciation program I have ever seen. I am an American Accent Trainer in India and have trained 22,000 agents. After taking this program, I wish there was a way to go back and start all over again."-Oorvakx Boyce, American Accent Trainer, India

"I am the Head of the Training Department of the World's Second Largest Call Center Company in India. We have footprints in over 40 countries around the world including many centers in United States as well. I have been working in the Call Center Industry in India for the past 8 years. Because we cater to America, for years we have been searching for a cost effective training method to learn the American style of English Pronunciation, however, have had no luck... that is, until we found the PronunciationWorkshop program. While searching through Google one day, I came across the PronunciationWorkshop website and watched the free demo ... We found that demo to be SIMPLY AMAZING STUFF !!!!!!! Instead of showing diagrams, visuals combined with phonetics, there was Paul. A LIVE TRAINER... SHOWING HIS MOUTH FORMATION and the TECHNIQUES to get a clearer sound. I quickly showed it to my CEO and he was amazed as well. What's unique about Paul's course is how simple it is... as well as fun to watch. My staff always looks forward to working on this program... We seem to learn something new every time we watch another video, and it has made remarkable changes in our speech and English skills. We have implemented this training approximately 6 months ago to improve our customer satisfaction scores. Not only have we seen significant improvements with our scores, but our Average Call Handle Time per customer has reduced approximately by $29 \%$ in the last 4 months as the agents do not need to repeat themselves. Looking into the success of the program at our center we have also asked Paul to develop a certification program. I myself, as well as members of my staff have gone through telephonic training with Paul, one-on-one. Paul makes learning so much FUN and has changed the way we speak English!!!. Today I am proud to say that the entire training department has become Certified by Pronunciation Workshop. I cannot praise this course enough... It is truly quite an achievement and I know you will be extremely pleased as well.-Joy Deb Mukherjee, Director of Training, India

"The truly remarkable thing about Paul's [the trainer] program is how simple $\&$ effective it is... and his engaging persona really pulls you in. Here in India, 
using this program we are able to take an individual who is UNEMPLOYABLE for the offshore booming call center industry, and make him EMPLOYABLE, with a good job which pays well, in less than two and half months... That's the Power of Paul's program!!! He is changing lives on the opposite side of the world!"-Sanjay Mehta, Managing Director, Teleperformance India

And American Accent (www.americanaccent.com) sees a direct link between its online teaching methodology and its prospective customers, the call center workers:

Example 11

\section{"It Works}

\section{Quick, Easy \& Fully Automated}

Given the powerful combination of high aptitude and a proven methodology, designated trainees easily and quickly pick up on the accent.

People used to think that classroom training is the best method, but for the ideal call center candidate, you want someone who is completely comfortable in the virtual environment-from initial training through to long-term job satisfaction."

All of this is, in a way, summarized and hyperbolically illustrated by the start page of the Pronunciation Workshop:

Example 12

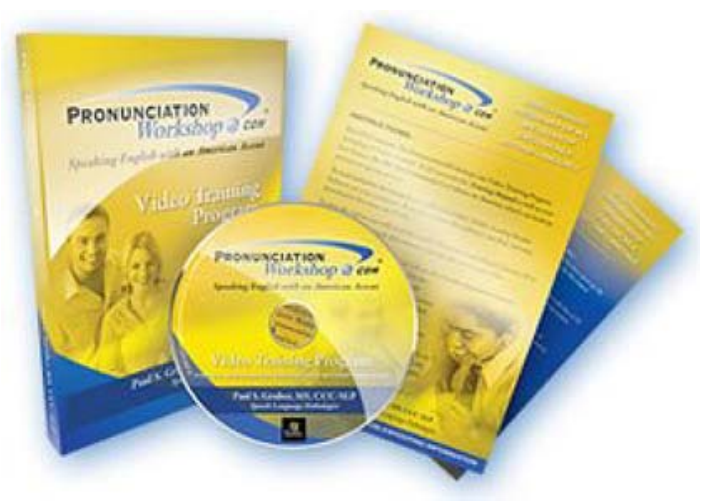

Our unique and powerful American Accent

Video Training Program

will dramatically improve the way you speak English.

\section{Proper English Pronunciation Is Your Key To A Bright Future}

If you could learn to pronounce American English with an American accent, many social and job opportunities would open up for you. 
"This program has helped me to increase my income by more than double in a short span of three months." -Sandeep Sisodia - Agra, India

\section{Pronunciation Workshop's expert English pronunciation techniques will quickly teach you Proper American English Pronunciation Soon you will be speaking American English clearly, correctly and confidently. Imagine how great that will feel!}

Our program will teach you correct American English pronunciations, intonations and expressions so that others can easily understand you.

This can help you enjoy Greater Success and Make More Money!

\section{Global indexicals of success}

American accent, personal happiness and self-confidence, smooth and efficient communication with Americans, job satisfaction, business opportunities and money: this is the package sold by these dot-com businesses. The package consists of 'language' itself (or register-bits thereof) as well as representations of it and of what it has to offer its speakers, and, at a very implicit level, representations of 'America', of what America is as a society and of the sociocultural preferences and expectations of 'Americans'. ${ }^{2}$ Following Silverstein (2006, p. 485) we can call this 'semiotic consubstantiality': you are (or become) what you speak, and speaking it (mysteriously) transforms you into what is indexically suggested by the speech. The providers sell these consubstantialities to the people who are at the heart of globalization processes: expatriate (i.e. deterritorialized or peripatetic) professionals hungry for success, opportunity and money, and call center operatives in 'delocalized' and inherently mobile areas of the business world. And they sell them by means of that defining technology of globalization: the internet. The target audiences for these websites are not the masses of poor migrants from the margins of the world, not the Philippine domestic workers who have become one of their nation's main export industries, not the housewives who join their expatriate husbands. The target audiences are the groups who embody globalization as a success story - they are, in other words, a very small segment of the flows of people that characterize contemporary globalization. And one of the advantages of these materials is that they begin to show us a picture of what 'success' means within this imagery of globalization. For what the websites do is to abundantly flag what Silverstein (2006, p. 486) calls (with respect to dictionary cautions such as 'slang' or 'obscene') "register alerts". Such alerts

\footnotetext{
${ }^{2}$ Note that none of the websites here mentioned offers 'plain speech', that most 'typical' Americanist symbolic speech economy embodied by public figures ranging from Joe McCarthy, Lyndon B. Johnson and Ronald Reagan to George W. Bush. See Silverstein (2003b) for a discussion on Bush's 'plain' rhetoric. The speech offered by these websites is clearly technical, high-brow and sophisticated, aimed at insertion in elite (not 'plain') networks.
} 
"give normative indexical properties of a lexeme's appropriateness-to and effectiveness-in co(n)texts (...) of occurrence: where to use it, and what, socially speaking, will happen when you do."

If we replace 'lexeme' with 'accent' we have, I believe, an accurate description of what these websites try to achieve: to overtly specify the rich indexicals that come with the language in normative terms; to explicitly describe, in sum, an order of indexicality for the use of such an accent: you must use this accent if you want to become the person you intend to be (Blommaert 2005, p. 69, 2007). Naturally, there is a hierarchization involved in this: not every kind of speech is adequate and only this kind of speech will do.

We see this clearly from the way in which the websites define the exercise they expect from and offer to coach to their customers. First, it is not just about acquiring a new accent, but even more about getting rid of another accent ("Lose your accent in 28 days!"). Hence the often used label of 'accent reduction' as a descriptor of the courses offered. The existing accents are wrong:

Example 13

"We focus on correcting your biggest speaking errors first. After the first lesson, you will already feel more confident about your speech" (Accurate English)

\section{Example 14}

"Nobody had ever been able to tell me what exactly was wrong with my speech until I took the Accurate English accent reduction course. There was a noticeable difference in my speech after only a few lessons. I see this course as an investment in my future. I learned how to strengthen my "Chinese tongue" to create the sounds of good American English." (Testimonial page, Accurate English)

They are also, as we saw in several of the examples earlier, an obstacle to personal and business success, a source of frustration (recall the image of the Asian woman!), something that can hamper individuals and corporations in their ambition. So what is at stake is, one could say, linguistic purification as the first step to linguistic readiness for the globalized world. And at the core of this process of purification we see an image of the regimented, subject, someone who can face the challenges of postmodern, globalized existence provided he/she submits to the process of purification and, consequently, sacrifices his/her individual agency in a quest for uniformity and homogeneity.

At this point, the locality and authenticity we encounter in popular, political and academic discourses on dialects and accents is far away. There is little value to the linguistic signs of belonging and authenticity that usually go under the label of 'accent'. Or at least: there is clearly a differential value to different accents. While foreign accents are remarkable, audible, and problematic, and hence need to be reduced or eliminated, American accent itself is unmarked, unremarkable, unnoticed. Once you acquire American accent, your speech becomes 'normal', invisible, unremarkable, and can so become a vehicle for 'efficient', 'smooth', 'clear', 'confident' and 'convincing' communication (see Accurate English's 
website banner: "Helping foreign professionals to communicate with confidence, clarity and accuracy"). American accent is not really an 'accent' like, e.g. a German-English or Indian-English accent-it is a neutral tool, a purely linguisticcommunicative instrument. Thus, in example 9 above, we saw how Communicaid projected trained employees "maximizing their communication with your customers through a neutral accent" while they minimize "the influence of their first language" (italics added). And in their FAQ section, American Accent reassures its customers as follows ${ }^{3}$ :

\section{Example 15}

Is this slang?

No, of course not. Standard American English pronunciation is different from spelling, but it is not slang.

American accent, thus, is the 'exnominated' accent, to use a term coined by Barthes (1957) to denote the bourgeoisie. The bourgeoisie, Barthes said, was so hegemonic that they ceased to be perceived and named as bourgeoisie; they were just 'the people'. American accent, then, is the accent that is no longer an accent but just a vehicle for doing stuff. It is just a 'normal', expected, customary and efficient language. If you use it well, it helps you achieve the goals you have set in life: prosperity, success, happiness. And while, as the Accent Reduction Institute claims, customers can "maintain their unique cultural identity", when they wish to be the globalized actors they aspire to be, they need to change and become sociolinguistically invisible. Their "unique cultural identity" should not transpire from their speech. As for American cultural identities, they can also be studied in courses provided by the websites:

\section{Example 16}

\section{"The American Psyche}

Typical culture pieces seek to inform a trainee of facts about America. This information, however, is readily available via the media and the Internet, and can be easily acquired once the student has a standard accent. The AAT culture piece, on the other hand, deals with the American psyche. Trainees learn how Americans think, what is important to them, and how best to get them to respond in the desired way." (American Accent)

Thus, one remains 'Indian' while one can sound 'American'. And to the extent that accents betray the life-histories of their users, and in particular the histories of institutionalized and mundane language usage and learning, sounding American means that all of this has to be backgrounded. An Indian accent in English is the result of language learning processes in India, and the accent displays all the sociolinguistic diacritics we know: age, gender, class, educational background and

\footnotetext{
${ }^{3}$ Note the curious statement that American pronunciation "is different from spelling". Observe also that none of the websites, in addition, makes reference to multilingualism as an outcome of learning American accent. The fact that the typical customer would not be a 'native speaker' and that, logically, the learning experience ought to result in new multilingual repertoires is nowhere thematised. The vision articulated here is clearly monoglot: American accent is more than enough and the only language that really matters here (Silverstein 1996).
} 
so on. An American accent course removes all of this identificatory uniqueness and replaces it by an exnominated and translocal, presumed neutral and uniform accent.

The effort that trainees should invest in this process of removal and replacement is considerable. Apart from a significant financial investment in registering for the courses, they are expected to buy books, CDs and DVDs, have telephone tutorials with their trainers, record their own speech and listen to it, seek informal communication opportunities with 'native speakers', and even attentively watch TV:

Example 17

"When you are watching T.V. look at the mouth movements of the speakers.

Repeat what they are saying, imitating the intonation and rhythm of their speech" (Accurate English)

But as we saw in example 10, the effort pays: "our Average Call Handle Time per customer has reduced approximately by $29 \%$ in the last 4 months as the agents do not need to repeat themselves". We also saw in several examples given earlier that individuals referred to their experience with such courses as events that made them gain self-confidence, the respect of their peers or superiors, and upward social mobility. Here is an ideologically rich and well-aged sign: the idea that hard work to change yourself will result in material as well as symbolic rewards. The American dream is here projected onto the symbolic currency marketed by these businesses: American accent.

Summarizing we see the following picture. Customers who subscribe to these courses buy a package consisting of language as well as of representations of language, society and selves. They are expected to change themselves by 'reducing' their existing accents in English, and by adopting, with great investments of effort, an accent that makes them sociolinguistically invisible and changes their speech from something that contains side-tracking 'noise' (their 'foreign accent') to a normal, uniform, unremarkable and thus no longer distracting tool of communication. This effort is rewarding, because it will remove the frustration resulting from (repeated) misunderstandings due to the 'noise' in their speech, it will allow Americans, thus, to see them for what they truly are, and this then will offer socially upward mobility. This, I would venture, is the cultural semantics of these courses, the ordered complex of indexicals suggested by American accent courses as a way to global success, provided it is converted into ordered, disciplined, policed use.

\section{Discussion}

This cultural semantics is a bit disconcerting, of course. We live in a world in which language learning environments, especially for English, become highly diversified and now include purely formal environments (official curricula and school programs) as well as purely informal ones (the global media and popular culture empires), with several hybrid forms in between such as the websites here 
examined. ${ }^{4}$ In this highly polycentric learning environment, some actors are subject to formal and sometimes rather rigid state policies- the formal learning environments typically are-while others escape such forms of imposed normativity. The websites discussed here, I suggest, contain a very clear and rather transparent language policing which, while being strictly speaking informal (in the sense of: not controlled by external authorities), is stable, predictable and hegemonic. It taps into widespread and very powerful images of globalization as centered on the US and revolving around English, corporate culture and individual spatial and social mobility. These images show traces of one of Appadurai's (1996) 'idioscapes'globally distributed sociocultural and ideological scenarios-notably of what Fairclough (2006) calls 'globalism': the kind of popular neo-liberal scenario of globalization often associated with the Reagan and Thatcher era and famously codified in Fukuyama's (1992) End of History. This is an effect undoubtedly of the particular composition of their projected audiences: prospective customers, as said earlier, do not belong to the 'losers' of globalization but rather to its 'winners': globally mobile professionals who have the wherewithal to make the best of the opportunities offered by globalization processes. But its remarkable uniformity betrays the self-evidence of a strong hegemony for such views among the community of users of these websites.

This, of course, should warn us against making quick generalizations about language in globalization. We are not facing the emergence of a wholesale new global order of discourse here (contrary to what Fairclough 2006 seems to believe), but rather a highly niched phenomenon that affects the lives of relatively restricted groups of people, and that is an effect of larger globalization processes - the deregulation of international business activity and labour, the development of virtual spaces for communication, commodification and learning such as the internet, and the power of more general ideologies and discourses such as globalism. Sociolinguistic globalization is not the engine behind globalization, but an epiphenomenon of larger processes that are of a far more fundamental nature and have a far greater historical depth. Most people in the world do not want to spend money to learn American accents. In effect, most people couldn't care less.

Having said that, phenomena such as the ones examined here still do teach us a thing or two about language in globalization. One thing we see here is that the object of globalized commodification is accent and not language. This is a commodified dialectology, not just language learning. The point merits attention, because much scholarly effort has been spent on describing sociolinguistic globalization processes as processes of the spread of English (e.g. Graddol 2006), often captured in metaphors of imperialism (e.g. Phillipson 1992, 2003). While there is merit in these views and some of the more nuanced statements offer us very helpful insights (e.g. Williams 2006; Pennycook 2007), investigations such as the ones reported here provide us with a more fine-grained view of sociolinguistic globalization processes. They are definitely not uniform, nor are they exclusively uniformizing: they are

\footnotetext{
${ }^{4}$ Pennycook (2007, Chap. 8) discusses ways in which formal and informal learning environments can be blended in what he calls 'Hip Hop pedagogies'.
} 
layered processes developing at several, very different scale-levels. The global purchase of English-what de Swaan (2001) called the 'stampede towards English' - is a phenomenon at one scale-level, a very general one and consequently one that, in actual sociolinguistic practice, would appear as a relatively widespread but superficial phenomenon. The marketing of American accents, on the contrary, revolves around specific sociolinguistic registers targeted at specific (rather small) groups. These groups, we can assume, already 'know English', but they require a more specific set of linguistic, pragmatic and metapragmatic skills - to sound like an American. The scale of such processes is far smaller than that of 'global Englishes', but the process appears a lot more developed and having a more profound impact. Given the homogenizing 'semiotic consubstantiality' we witnessed in these dot-com Englishes, we could say that this (rather than the 'imperialist' spread of English tout court) is real 'McDonaldization': customers are expected not just to buy the language but also the whole indexical (that is: ideological) package it contains, and to do so from within a narrowly defined 'globalist' worldview. These are different processes, to be sure-perhaps complimentary but of a different order. And I would suggest that a sound sociolinguistics of globalization should not just look at the world and its languages, but also to the world and its registers, genres, repertoires and styles, if it wants to have any empirical grounding. It is in small-scale, niched phenomena such as the ones considered here that we see real language: language that is invested by real-world interests and language that matters to real people. This, naturally, is no longer the 'linguistic' language, neither is it the language-political language, but it is the sociolinguistic language and the language of the everyday politics of language, produced and articulated in a polycentric environment by a multitude of (often ephemeral) actors.

This leads us to a second point about globalization. Given the intense polycentricity of learning environments and the fact that globalization processes develop at several different scale-levels, the issue of normativity becomes quite complex. What is the status of language norms, who produces them and who enforces them? These are questions that now require a detailed examination of actors, instruments, goals and resources. American accent websites cater for a market that is not serviced by the national formal learning systems. Indians who have acquired English at school and seek employment in global call centers need to be retrained in American accent, because their school English bears too many traces of what in our examples was called 'strong foreign accent'. Thus we see how actors collaborate in the production of language norms in an interdependent complex of actors: the school system produces 'English', using its own pedagogies and orders of indexicality; but in order to acquire the specific kind of English that offers jobs in the globalized economy, people need to turn to private providers, who impose yet another set of norms and rules of proper speech. These private providers- the internet companies we discussed here, but think also of privately run international schools in postcolonial societies - are not tied to the national order of things, their activities are 'border busting' in nature, and interestingly their cultural semantics revolves around uniformity, homogeneity and submission-a very modernist response to globalized, post-modern pressures. 
An important feature of globalization processes is the fact that they blend the local and the translocal in complex networks (Castells 1996). Local sociolinguistic systems, consequently, are shot through by traces and fragments of translocal ones, and the language that is 'good' in the local sociolinguistic system may not be good enough in the translocal ones-which is why Indian call center workers need to learn American English and should not use their local accents. We see various normative complexes (I called them orders of indexicality) operate in the same environment, often without manifest overlap or confusion but 'niched' and confined to particular sets of communicative tasks. Highly skilled individuals such as the globalized professionals targeted by the American accent marketeers acquire, and must acquire, the resources that allow them to operate within and across these different orders of indexicality. Language, predictably, thus becomes something that requires continuously more investment from its users, and language learning (or rather: the learning of specific registers tailored to particular communicative tasks) will increasingly become a balancing act between formal and informal learning processes. It becomes, in effect, a permanent 'care of the self' in Foucault's (2006) sense, a permanent quest for order by attending to the small details of linguistic conduct. Highly specialized providers such as the ones described in this paper, who are able to offer these microscopic definitional registers of subjectification as operational (linguistic) and ideological (indexical) packages may thrive in this brave new world of language.

Open Access This article is distributed under the terms of the Creative Commons Attribution Noncommercial License which permits any noncommercial use, distribution, and reproduction in any medium, provided the original author(s) and source are credited.

\section{References}

Agha, A. (2005). Voice, footing, enregisterment. Journal of Linguistic Anthropology, 15, 38-59. doi: 10.1525/jlin.2005.15.1.38.

Agha, A. (2007). Language and social relations. Cambridge: Cambridge University Press.

Appadurai, A. (1996). Modernity at large. Minneapolis: University of Minnesota Press.

Barthes, R. (1957). Mythologies. Paris: Le Seuil.

Blommaert, J. (2005). Discourse: A critical introduction. Cambridge: Cambridge University Press.

Blommaert, J. (2007). Sociolinguistics and discourse analysis: Orders of indexicality and polycentricity. Journal of Multicultural Discourses, 2(2), 115-130. doi:10.2167/md089.0.

Bourdieu, P. (1991). Language and symbolic power. Cambridge: Polity.

Castells, M. (1996). The rise of the network society. London: Blackwell.

de Swaan, A. (2001). Words of the world. Cambridge: Polity Press.

Elmes, S. (2005). Talking for Britain: A journey through the nation's dialects. Harmondsworth: Penguin Books.

Fairclough, N. (2006). Language and globalisation. London: Routledge.

Foucault, M. (2006). The hermeneutics of the subject. London: Palgrave.

Foucault, M. (2007). Security, territory, population. London: Palgrave.

Fukuyama, F. (1992). The end of history and the last man. New York: Free Press.

Graddol, D. (2006). English next: Why global English may mean the end of 'english as a foreign language. London: British Council.

Pennycook, A. (2007). Global Englishes and transcultural flows. London: Routledge.

Phillipson, R. (1992). Linguistic imperialism. Oxford: Oxford University Press.

Phillipson, R. (2003). English-only Europe? London: Routledge. 
Silverstein, M. (1996). Monoglot 'standard' in America: Standardization and metaphors of linguistic hegemony. In D. Brenneis \& R. Macaulay (Eds.), The matrix of language (pp. 286-306). Boulder: Westview.

Silverstein, M. (2003a). Indexical order and the dialectics of sociolinguistic life. Language \& Communication, 23, 193-229. doi:10.1016/S0271-5309(03)00013-2.

Silverstein, M. (2003b). Talking politics: The substance of style from Abe to ' $W$ '. Chicago: Prickly Paradigm Press.

Silverstein, M. (2006). Old wine, new ethnographic lexicography. Annual Review of Anthropology, 35, 481-496. doi:10.1146/annurev.anthro.35.081705.123327.

Williams, E. (2006). Bridges and barriers: Languages in African education and development. Manchester: StJerome.

\section{Author Biography}

Jan Blommaert is Finland Distinguished Professor of Linguistic Anthropology at the University of Jyväskylä, Finland, and Professor of Linguistic Anthropology at Tilburg University, The Netherlands. His research addresses theoretical and empirical aspects of language and globalization, with special emphasis on inequalities in this field, and with materials from Africa, Asia and Europe. His major publications include 'Language Ideological Debates' (Mouton de Gruyter 1999), 'Discourse: A critical Introduction' (Cambridge University Press, 2005), 'Grassroots Literacy: Writing, Identity and Voice in central Africa' (Routledge 2008) and 'A Sociolinguistics of Globalization' (Cambridge University Press, forthcoming 2009). 